\title{
Game Theoretic Analysis of Standby Systems
}

\author{
Kjell Hausken \\ Faculty of Social Sciences \\ University of Stavanger \\ Stavanger \\ Norway
}

\section{Introduction}

Systems have traditionally been analyzed assuming only one player, i.e. the defender maximizing system reliability facing exogenously fixed factors related to technology, nature, weather, culture, etc. After the September 11, 2001 attack realizations emerge that whereas one set of players work to ensure system reliability, another set of players oppose system reliability. This paper thus provides a game-theoretic analysis of a main system and a standby system. Examples of systems are power supply, telecommunications systems, water supply, roads, bridges, tunnels, political and economic institutions, businesses, schools, hospitals, recreational facilities, and various assets.

Many strategic considerations exist for a main system and a standby system. The players can choose their efforts in the present, or in the future dependent on the outcome of the strategic interactions in the present. For example, the defender of a water supply system will be intent on protecting it in the present since if it fails, the standby system has to take over in the future.

Compared with the literature the contribution of this paper is to provide an understanding of how the strategic interactions in the present are linked to the strategic interactions in the future for a main system and a standby system. This is done by analyzing a defender and an attacker in a two period game. The first period expresses the present and the second period expresses the future. The main system can fail dependent on the strategic interactions in the first period. This in turn impacts the strategic interactions in the second period. Furthermore, looking ahead to the second period before the game starts influences the players' strategies in the first period.

Systems where the future state of affairs depend on the present state of affairs are referred to as dependent systems (Ebeling 1997). Dependent systems have a long tradition of being analyzed using Markov analysis, which is unrelated to game theory. ${ }^{1}$ A simple definition of

\footnotetext{
${ }^{1}$ First the number of system states is specified. Second the reliability is determined based on the system configuration. Third a rate diagram is designed where each node represents a state and each branch with an arrow specifies a transition rate (failure rate) expressed with a parameter. Fourth an equation is formulated for the probability of being in each state at time $t+\Delta t$ which equals the probability of being in the state at time $t$, adding or subtracting the probabilities of moving into or out of the state from neighboring states when accounting for the transition rates. Fifth each equation is reformulated as a
} 
a stochastic process with the Markov property is that the conditional probability distribution of future states of the process depends only upon the present state. ${ }^{2}$ Markov analysis has proven highly successful applied to reliability analysis. This paper is concerned with two limitations of Markov analysis. First, enabling each of two players to choose strategies in each of two periods violates the Markov property since players are free to choose future strategies that are not conditioned on their present strategies. Generally, any theory involving intentional action (e.g. game theory) violates the Markov property. Second, this paper relaxes the constraint in Markov modeling where the transition rates between different states are kept constant through time.

This paper enables players to exert efforts to impact the system reliability as time progresses. That is, we analyze how players choose strategies through time to impact the reliability of dependent systems. We consider a dependent system consisting of a main system and a standby system. Both the main system and the standby system can be in two states which are to operate or fail. The dependent system is analyzed for general parameter values with backward induction as a two period game. We determine how two players make strategic decisions through time to impact the system reliability. Players allocate resources in the sense of substituting efforts across components and across time. Determining the nature of such substitutions is of substantial interest, see e.g. Enders and Sandler (2003), Hausken (2006), and Keohane and Zeckhauser (2003).

The paper answers questions such as whether players exert high efforts in the first period to position themselves for the second period, whether they are so weakened that they withdraw from the game, or whether they prefer the game to last one period or two periods. One player, the defender, maximizes the system reliability. The other player, the attacker, minimizes the system reliability. Both the main system's and the standby system's reliabilities depend on the relative levels of defense and attack and on the contest intensities. Each player's utility depends additively on the system reliability in the two periods, with a discount parameter varying between 0 and 1 for the second period. The unit costs of defense and attack, and the contest intensities, are different for the main system and the standby system, analogously to failure rates being different in Markov analysis dependent on the system state.

Hausken (2010) analyzes complex systems applying game theory. Hausken (2011) provides a game theoretic analysis of a two period dependent system of two components which can be fully operational, in two states of intermediate degradation, or fail.

For multi-state system reliability, see Lisnianski and Levitin (2003). For degraded systems see Ebeling's (1997:117ff) Markov analysis of a system which can be fully operational,

differential equation. The number of equations equals the number of states minus 1 . The probability of being in the last state equals 1 minus the sum of the probabilities of being in the other states. Examples of systems analyzed with Markov analysis are load sharing systems, standby systems, degraded systems, and multistate systems (Ebeling 1997:108ff). For example, if one component fails in a load sharing system, the failure rates increase for the remaining components. A standby component may experience a low or zero failure rate in its standby state, and a higher failure rate when operational (which may or may not equal the failure rate of the originally operating component).

2 Another definition is that of memorylessness where, conditional on the present state of the system, its future and past are independent. See e.g. Taylor and Karlin (1998) for further definitions. 
degraded, ot failed. See Zio and Podofillini (2003) for Monte Carlo simulation of the effects of different system performance levels on the importance of multi-state components. Ramirez-Marquez and Coit (2005) use Monte-Carlo simulation to approximate multi-state two-terminal reliability. A next step is to incorporate strategic defenders and attackers into the analysis of multi-state and degraded systems.

In earlier research Levitin (2007) considers the optimal element separation and protection in a complex multi-state series-parallel system, and suggests an algorithm for determining the expected damage caused by a strategic attacker. Hausken and Levitin (2009) present a minmax optimization algorithm. The defender minimizes the maximum damage the attacker can inflict thereafter. The defender has multiple defense strategies which involve separation and protection of system elements. The attacker also has multiple attack strategies against different groups of system elements. A universal generating function technique is applied for evaluating the losses caused by system performance reduction. Levitin and Hausken (2009) introduce three defensive measures, i.e. providing redundancy, protecting genuine elements and deploying false elements and analyze the optimal resource distribution among these measures in parallel and k-out of-N systems. Levitin (2009) considers optimizing defense strategies for complex multi-state systems.

Azaiez and Bier (2007) consider the optimal resource allocation for security in reliability systems. Bier et al. (2005) analyze the protection of series and parallel systems with components of different values. They specify optimal defenses against intentional threats to system reliability, focusing on the tradeoff between investment cost and security. Bier et al. (2006) assume that a defender allocates defense to a collection of locations while an attacker chooses a location to attack. Hausken (2008) considers defense and attack for series and parallel reliability systems. Dighe et al. (2009) consider secrecy in defensive allocations as a strategy for achieving more cost-effective attacker deterrence.

Section 2 presents the model. Section 3 solves the model. Section 4 analyzes three special cases. Section 5 simulates the solution. Section 6 considers examples. Section 7 concludes.

\section{The model}

Consider a main system and a standby system. A defender and an attacker play a two period game. In period $j, j=1,2$, the defender exerts effort $t_{\mathrm{Mj}}$ at unit cost $c_{\mathrm{M}}$ to defend the main system, where $t_{\mathrm{Mj}}$ is the defender's free choice variable. Analogously, the attacker exerts effort $T_{\mathrm{Mj}}$ at unit cost $C_{\mathrm{M}}$ to attack the main system, where $T_{\mathrm{Mj}}$ is the attacker's free choice variable. If the main system is successfully defended in period 1 it continues to operate in period 2, while the standby system continues to be on standby. If the main system is successfully attacked in period 1 it does not operate in period 2, and instead the standby system operates in period 2. This means that the defender exerts effort $t_{\mathrm{S} 2}$ at unit cost cs to defend the standby system, and the attacker exerts effort $T_{S 2}$ at unit cost $C_{S}$ to attack the standby system. Defense and attack are interpreted broadly. Defense means protecting against the attack, and maintaining and adjusting the system to prevent that it breaks down. Attacking means attacking the system, which may get aided by natural factors (technology, weather, temperature, humidity, etc.) to ensure that the system breaks down. We assume that the standby system does not operate in period 1 but is located in a secure place (e.g. underground bunker) from which it can be accessed if it is needed in period 2. We do not 
model efforts the defender and attacker may exert with respect to the standby system in period 1. In both periods both players make their strategic choices simultaneously and independently. Before the second period both players know the strategies chosen and the outcome of the first period. We formulate the reliability $p_{\mathrm{Mj}}$ of the main system in period $j$, and the reliability $p_{\mathrm{S} 2}$ of the standby system in period 2, as contests between the defender and attacker. The most common functional form is the ratio form (Tullock 1980)

$$
p_{M j}=\frac{t_{M j}^{m_{M}}}{t_{M j}^{m_{M}}+T_{M j}^{m_{M}}}, j=1,2, \quad p_{S 2}=\frac{t_{S 2}^{m_{S}}}{t_{S 2}^{m_{S}}+T_{S 2}^{m_{S}}},
$$

where $\partial p_{M j} / \partial t_{M j}>0, \partial p_{M j} / \partial T_{M j}<0, \partial p_{S 2} / \partial t_{S 2}>0, \partial p_{S 2} / \partial T_{S 2}<0$, and $m_{I} \geq 0, I=M, S$ is a parameter for the contest intensities of the main system $(M)$ and standby system $(S)$. The reliabilities $p_{\mathrm{Mj}}$ and $p_{\mathrm{S} 2}$ can also be interpreted as probabilities of system survival. Equation (1) is common in the rent seeking literature where the rent is an asset which corresponds to reliability in this paper. Conflict exists over reliability between the defender and the attacker, just as conflict exists over a rent between contending players. See Tullock (1980) for the use of $m_{\mathrm{I}}$, Skaperdas (1996) for an axiomatization, Nitzan (1994) for a review, Hirshleifer (1995) for illustration, usefulness, and application, and Hausken (2005) for recent literature. At the limit, with infinitely much defensive effort, and finite offensive effort, system $I$ is $100 \%$ reliable. The same result follows with finite defensive effort and zero offensive effort. At the other limit, with infinitely much offensive effort, and finite defensive effort, component $i$ is $0 \%$ reliable. The same result follows with finite offensive effort and zero defensive effort. The sensitivity of $p_{\mathrm{ij}}$ to $t_{\mathrm{ij}}$ increases as $m_{\mathrm{I}}$ increases. When $m_{\mathrm{I}}=0$, the efforts $t_{\mathrm{ij}}$ and $T_{\mathrm{ij}}$ have equal impact on the reliability regardless of their size which gives $50 \%$ reliability, $p_{\mathrm{ij}}=1 / 2.0<m_{\mathrm{I}}<1$ gives a disproportional advantage of exerting less effort than one's opponent. When $m_{\mathrm{I}}=1$, the efforts have proportional impact on the reliability. $m_{\mathrm{I}}>1$ gives a disproportional advantage of exerting more effort than one's opponent. This is often realistic in praxis, as evidenced by benefits from economies of scale. Finally, $m_{\mathrm{I}}=\infty$ gives a step function where "winner-takes-all".

The main system can in period 1 be in the two states shown in Table 1 , where $v_{M}$ and $V_{M}$ are the defender's and attacker's values of an operational main system given presence of a standby system.

$\begin{array}{lllll}\text { State } & \text { Main system } & \text { Reliability } & \text { Defender value } & \text { Attacker value } \\ 1 & \text { operates } & p_{\mathrm{M} 1} & v_{\mathrm{M}}-c_{\mathrm{M}} t_{\mathrm{M} 1} & -C_{\mathrm{M}} T_{\mathrm{M} 1} \\ 2 & \text { fails } & 1-p_{\mathrm{M} 1} & -c_{\mathrm{M}} t_{\mathrm{M} 1} & V_{\mathrm{M}}-C_{\mathrm{M}} T_{\mathrm{M} 1}\end{array}$

Table 1. Main system in two states in period 1.

We express the players' period 1 utilities as

$$
\begin{aligned}
& u_{1}=v_{M} p_{M 1}-c_{M} t_{M 1} \\
& U_{1}=V_{M}\left(1-p_{M 1}\right)-C_{M} T_{M 1}
\end{aligned}
$$

The players' period 1 strategic choices determine both their first period utilities and the system state as the start of period 2. Each time period can be short or long, e.g. one minute, one month, one shift, one season. If the main system fails in period 1, it cannot be repaired in 
time for the onset of period 2. This assumption is justified since repairing or replacing failed components can be complicated for economical and logistical reasons, and may require competence and time, which we assume is impossible both during the periods and in the transition from period 1 to period $2 .{ }^{3}$ Hence the strategies the players choose for period 1 have to account for the combinations of possibilities in which the main system may operate or fail in the two periods, and the standby system may operate or fail in period 2. If the main system fails in period 1 , since it cannot be repaired or replaced before the commencement of period 2, the players need to assess their defense and attack in period 2 to account for which of the two states (operation or failure) follows after period 1. In period 2 the players also make their strategic choices simultaneously and independently, knowing the outcome and choices in period 1 .

If the main system operates after period 1 (state 1 ), then the unit costs of defense and attack remain unchanged and the players make strategic choices $t_{\mathrm{M} 2}$ and $T_{\mathrm{M} 2}$. If the main system fails in period 1 (state 2), we assume that the unit costs of defense and attack for the standby system are $c_{\mathrm{S}}$ and $C_{\mathrm{S}}$, and the contest intensity is $m_{\mathrm{S}}$. The defender and attacker values of the standby system are $v_{\mathrm{S}}$ and $V_{\mathrm{S}}$, where $v_{\mathrm{S}} \leq v_{\mathrm{M}}$ and $V_{\mathrm{S}} \leq V_{\mathrm{M}}$. The defender and attacker values after period 2 are shown in Table 2, where $\delta$ and $\Delta$ are time discount parameters.

$\begin{array}{lllll}\text { State } & \begin{array}{l}\text { Main system } \\ \text { after period 1 }\end{array} & \begin{array}{l}\text { Reliability } \\ \text { after period 1 }\end{array} & \begin{array}{l}\text { Defender value } \\ \text { in period 2 }\end{array} & \begin{array}{l}\text { Attacker value } \\ \text { in period 2 }\end{array} \\ 1 & \text { operates } & p_{\mathrm{M} 1} & \begin{array}{l}\delta\left(v_{\mathrm{M}} p_{\mathrm{M} 2}-c_{\mathrm{M}} t_{\mathrm{M} 2}\right) \\ \delta\left(v_{\mathrm{S}} p_{\mathrm{S} 2}-c_{s} t_{\mathrm{S} 2}\right)\end{array} & \begin{array}{l}\Delta\left(V_{\mathrm{M}}\left(1-p_{\mathrm{M} 2}\right)-C_{\mathrm{M}} T_{\mathrm{M} 2}\right) \\ \Delta\left(V_{\mathrm{S}}\left(1-p_{\mathrm{S} 2}\right)-C_{\mathrm{S}} T_{\mathrm{S} 2}\right)\end{array}\end{array}$

Table 2. Defender and attacker values after period 2.

We thus express the players' utilities over the two periods as

$$
\begin{aligned}
& u=v_{M} p_{M 1}-c_{M} t_{M 1}+\delta p_{M 1}\left(v_{M} p_{M 2}-c_{M} t_{M 2}\right)+\delta\left(1-p_{M 1}\right)\left(v_{S} p_{S 2}-c_{S} t_{S 2}\right), \\
& U=V_{M}\left(1-p_{M 1}\right)-C_{M} T_{M 1}+\Delta p_{M 1}\left(V_{M}\left(1-p_{M 2}\right)-C_{M} T_{M 2}\right)+\Delta\left(1-p_{M 1}\right)\left(V_{S}\left(1-p_{S 2}\right)-C_{S} T_{S 2}\right)
\end{aligned}
$$

The third term on the right hand side in both utilities contains $p_{\mathrm{M} 1}$ which is the probability that the main system survives period 1 . The fourth and rightmost term on the right hand side in both utilities contains 1- $p_{\mathrm{M} 1}$ which is the probability that the main system does not survive period 1. Fig. 1 shows the two-period game as an extensive form game tree.

\section{Solving the model}

The two players have two strategic choice variables $t_{\mathrm{M} 1}$ and $T_{\mathrm{M} 1}$ in period 1 , and four strategic choice variables $t_{\mathrm{M} 2}, T_{\mathrm{M} 2}, t_{\mathrm{S} 2}$, and $T_{\mathrm{S} 2}$ in period 2 . We analyze pure strategy Nash equilibria. We solve the game with backward induction starting with period 2 . Differentiating gives $\partial u / \partial t_{M 2}=\partial u / \partial t_{S 2}=0$ and $\partial U / \partial T_{M 2}=\partial U / \partial T_{S 2}=0$. Solving the four equations gives

\footnotetext{
${ }^{3}$ Future research may model the repair of the main system.
} 


$$
\begin{aligned}
& T_{I 2}=\frac{m_{I}\left(\frac{C_{I} / V_{I}}{c_{I} / v_{I}}\right)^{m_{I}} V_{I}}{C_{I}\left(1+\left(\frac{C_{I} / V_{I}}{c_{I} / v_{I}}\right)^{m_{I}}\right)^{2}}, \quad t_{I 2}=\frac{C_{I} / V_{I}}{c_{I} / v_{I}} T_{I 2}, \quad p_{I 2}=\frac{1}{1+\left(\frac{C_{I} / V_{I}}{c_{I} / v_{I}}\right)^{m_{I}}}, \quad I=M, S \\
& u_{I 2}=v_{I} p_{I 2}-c_{I} t_{I 2}=\frac{1+\left(1-m_{I}\right)\left(\frac{C_{I} / V_{I}}{c_{I} / v_{I}}\right)^{m_{I}}}{\left(1+\left(\frac{C_{I} / V_{I}}{c_{I} / v_{I}}\right)^{m_{I}}\right)^{2}} v_{I}, \\
& U_{I 2}=V_{I}\left(1-p_{I 2}\right)-C_{I} T_{I 2}=\frac{1-m_{I}+\left(\frac{C_{I} / V_{I}}{c_{I} / v_{I}}\right)^{m_{I}}}{\left(1+\left(\frac{C_{I} / V_{I}}{c_{I} / v_{I}}\right)^{m_{I}}\right)^{2}}\left(\frac{C_{I} / V_{I}}{c_{I} / v_{I}}\right)^{m_{I}} V_{I}
\end{aligned}
$$

where $u_{12}$ and $U_{12}$ are the period 2 utilities for system $I, I=M, S$. The second order conditions are satisfied when

$$
\left(\frac{m_{I}-1}{m_{I}+1}\right)^{1 / m_{I}}<\frac{C_{I} / V_{I}}{c_{I} / v_{I}}<\left(\frac{m_{I}+1}{m_{I}-1}\right)^{1 / m_{I}}, I=M, S
$$

Equation (5) is satisfied with an infinitely large range for the commonly used contest intensity $m_{\mathrm{j}}=1$, and generally stretches from below to above $\frac{C_{I} / V_{I}}{c_{I} / v_{I}}=1$.

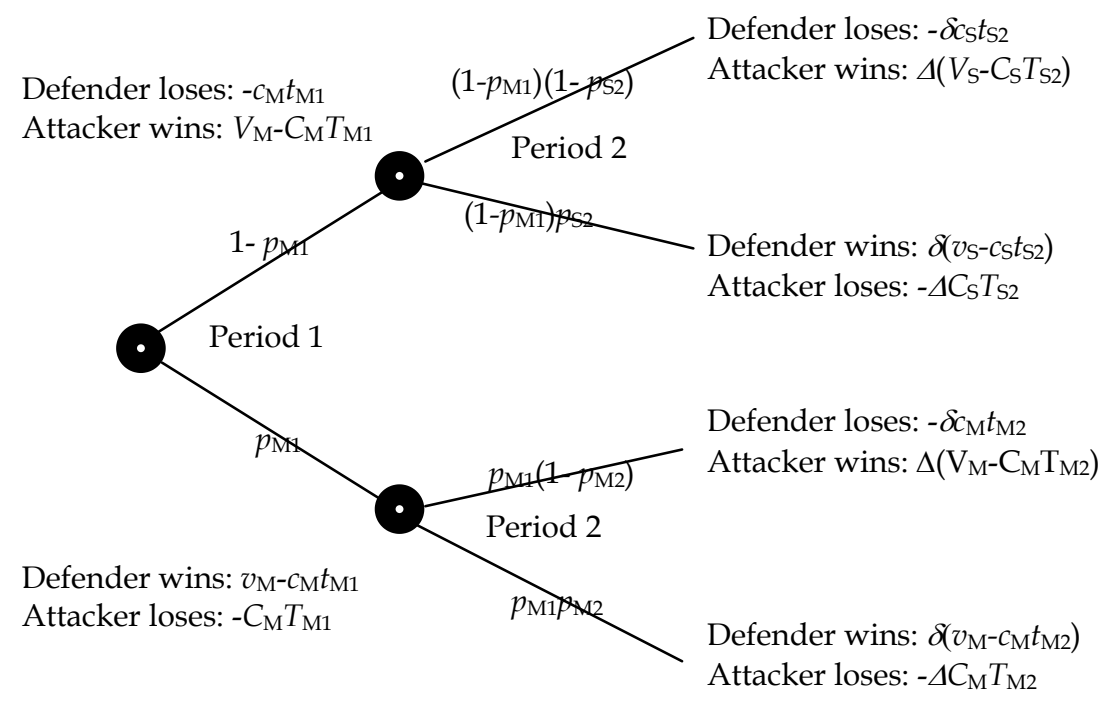

Fig. 1. The two-period extensive form game tree. 
Equations (3) and (4) show that the second period strategic choice variables do not depend on the first period strategic choice variables, only on the parameters. This means that the two-period game gives the same result as a corresponding one-period game where the players choose their six strategies simultaneously and independently. This result follows since the players' strategic choices in period 2 are independent for the two states that are possible after period 1 . For state 1 the strategic choice variables are $t_{\mathrm{M} 2}$ and $T_{\mathrm{M} 2}$. For state 2 the strategic choice variables are $t_{\mathrm{S} 2}$ and $T_{\mathrm{S} 2}$. Consequently the players do not need to know the outcome of period 1 in order to play period 2. But, the probabilities of the two states depend on how period 1 is played, so the players account for the outcome of period 2 for each of the two states when determining their strategies in period 1. Thus the expressions for $t_{\mathrm{M} 2}$ and $T_{\mathrm{M} 2}$ are valid for a one period main system as described in Table 1, and the expressions for $t_{\mathrm{S} 2}$ and $T_{\mathrm{S} 2}$ are valid for a one period system of a standby system.

To solve period 1 we rewrite (3) as

$$
\begin{aligned}
& u=a p_{M 1}+b-c_{M} t_{M 1}, \quad U=A\left(1-p_{M 1}\right)+B-C_{M} T_{M 1}, \\
& a=v_{M}+\delta\left(v_{M} p_{M 2}-c_{M} t_{M 2}-v_{S} p_{S 2}+c_{S} t_{S 2}\right), \quad b=\delta\left(v_{S} p_{S 2}-c_{S} t_{S 2}\right), \\
& A=V_{M}+\Delta\left(-V_{M}\left(1-p_{M 2}\right)+C_{M} T_{M 2}+V_{S}\left(1-p_{S 2}\right)-C_{S} T_{S 2}\right), \quad B=\Delta\left(V_{M}\left(1-p_{M 2}\right)-C_{M} T_{M 2}\right)
\end{aligned}
$$

where $a, b, A, B$ are parameters determined by inserting (4) into (6). We interpret $a$ and $A$ as the defender's and attacker's values of an operational two period system consisting of a main system and a standby system. The parameters $b$ and $B$ provide direct values to the defender and attacker, respectively. Differentiating gives $\partial u / \partial t_{M 1}=\partial U / \partial T_{M 1}=0$. Solving the two equations gives

$$
\begin{aligned}
& T_{M 1}=\frac{m_{M}\left(\frac{C_{M} / A}{c_{M} / a}\right)^{m_{M}} A}{C_{M}\left(1+\left(\frac{C_{M} / A}{c_{M} / a}\right)^{m_{M}}\right)^{2}}, \quad t_{M 1}=\frac{C_{M} / A}{c_{M} / a} T_{M 1}, \quad p_{M 1}=\frac{1}{1+\left(\frac{C_{M} / A}{c_{M} / a}\right)^{m_{M}}}, \\
& u_{1}=\frac{v_{M}+\left(v_{M}-a m_{M}\right)\left(\frac{C_{M} / A}{c_{M} / a}\right)^{m_{M}}}{\left(1+\left(\frac{C_{M} / A}{c_{M} / a}\right)^{m_{M}}\right)^{2}}, \quad U_{1}=\frac{V_{M}-A m_{M}+V_{M}\left(\frac{C_{M} / A}{c_{M} / a}\right)^{m_{M}}}{\left(1+\left(\frac{C_{M} / A}{c_{M} / a}\right)^{m_{M}}\right)^{2}}\left(\frac{C_{M} / A}{c_{M} / a}\right)^{m_{M}} \text {, } \\
& u=\frac{1+\left(1-m_{M}\right)\left(\frac{C_{M} / A}{c_{M} / a}\right)^{m_{M}}}{\left(1+\left(\frac{C_{M} / A}{c_{M} / a}\right)^{m_{M}}\right)^{2}} a+b, \quad U=\frac{1-m_{M}+\left(\frac{C_{M} / A}{c_{M} / a}\right)^{m_{M}}}{\left(1+\left(\frac{C_{M} / A}{c_{M} / a}\right)^{m_{M}}\right)^{2}}\left(\frac{C_{M} / A}{c_{M} / a}\right)^{m_{M}} A+B
\end{aligned}
$$

where 


$$
\begin{gathered}
a=v_{M}+\delta\left(\frac{1+\left(1-m_{M}\right)\left(\frac{C_{M} / V_{M}}{c_{M} / v_{M}}\right)^{m_{M}}}{\left(1+\left(\frac{C_{M} / V_{M}}{c_{M} / v_{M}}\right)^{m_{M}}\right)^{2}} v_{M}-\frac{1+\left(1-m_{S}\right)\left(\frac{C_{S} / V_{S}}{c_{S} / v_{S}}\right)^{m_{S}}}{\left(1+\left(\frac{C_{S} / V_{S}}{c_{S} / v_{S}}\right)^{m_{S}}\right)^{2}} v_{S}\right), \\
A=V_{M}+\Delta\left(\frac{1-m_{S}+\left(\frac{C_{S} / V_{S}}{c_{S} / v_{S}}\right)^{m_{S}}}{\left(1+\left(\frac{C_{S} / V_{S}}{c_{S} / v_{S}}\right)^{m_{S}}\right)^{2}}\left(\frac{C_{S} / V_{S}}{c_{S} / v_{S}}\right)^{m_{S}} V_{S}-\frac{1-m_{M}+\left(\frac{C_{M} / V_{M}}{c_{M} / v_{M}}\right)^{m_{M}}}{\left(1+\left(\frac{C_{M} / V_{M}}{c_{M} / v_{M}}\right)^{m_{M}}\right)^{2}}\left(\frac{C_{M} / V_{M}}{c_{M} / v_{M}}\right)^{m_{M}} V_{M}\right), \\
b=\delta \frac{1+\left(1-m_{S}\right)\left(\frac{C_{S} / V_{S}}{c_{S} / v_{S}}\right)^{m_{S}}}{1-m_{M}+\left(\frac{C_{M} / V_{M}}{c_{M} / v_{M}}\right)^{m_{M}}}\left(\frac{C_{M} / V_{M}}{c_{M} / v_{M}}\right)^{m_{M}} V_{M} \\
\left(1+\left(\frac{C_{S} / V_{S}}{c_{S} / v_{S}}\right)^{m_{S}}\right)^{2} v_{S}
\end{gathered}
$$

Inserting $\delta=\Delta=0$ into (8) gives $a=v_{\mathrm{M}}, A=V_{\mathrm{M}}, b=B=0, T_{\mathrm{M} 1}=T_{\mathrm{M} 2}$, and $t_{\mathrm{M} 1}=t_{\mathrm{M} 2}$, confirming that period 1 operates as the last period 2 with maximum discounting. Equation (8) implies $\lim _{m_{M} \rightarrow \infty} a=0$ (since a cannot be negative) and $\lim _{m_{M} \rightarrow \infty} A=\infty$ and thus high contest intensity for the main system causes the defender and attacker to perceive the two period system as valueless and very valuable, respectively. Conversely, (8) also implies $\lim _{m_{s} \rightarrow \infty} a=\infty$ (since $a$ cannot be negative) and $\lim _{m_{S} \rightarrow \infty} A=0$ (since A cannot be negative) and thus high contest intensity for the standby system causes the defender and attacker to perceive the two period system as very valuable and valueless, respectively.

The second order conditions are satisfied when

$$
\left(\frac{m_{M}-1}{m_{M}+1}\right)^{1 / m_{M}}<\frac{C_{M} / A}{c_{M} / a}<\left(\frac{m_{M}+1}{m_{M}-1}\right)^{1 / m_{M}}
$$

The boundary solutions are as follows. The interior solution above is valid when $u \geq 0$ and $U \geq 0$ in (7). When $u<0$ or $U<0$, no pure-strategy Nash equilibrium exists. Analyzing mixed strategy equilibria is beyond the scope of this paper. Equation (7) and the next sections show that $u<0$ and $U<0$ are possible when the contest intensity of the main system $m_{\mathrm{M}}$ is large which induces large costly efforts. The case $u<0$ is calamitous for the defender since it cannot earn positive utility. We assume that the defender withdraws in this case, exerting zero effort and earning zero utility, while the attacker exerts negligible effort earning utility $V_{\mathrm{M}}+\Delta V_{\mathrm{S}}$ since all reliabilities are zero. One may reason that if the defender knows that the attacker exerts negligible effort, the defender can exert positive effort and earn positive utility. However, if the attacker knows that, it can exert positive effort and earn positive 
utility. In the absence of a pure-strategy Nash equilibrium, the assumption of withdrawal is plausible. Analogously, for the case $U<0$, we assume that the attacker withdraws exerting zero effort and earning zero utility, while the defender exerts negligible effort earning utility $(1+\delta) v_{\mathrm{M}}$ since all reliabilities are one.

\section{Analyzing three special cases}

Let us consider three special benchmark cases with straightforward interpretations. The first is the egalitarian case $m_{\mathrm{M}}=m_{\mathrm{S}}=0$ causing zero efforts and thus $50 \%$ probability of failure for the main system in period 1, and for the main system or standby system in period 2. This case illustrates how the players' utilities depend on the main system and standby system and the weights assigned to period 2 expressed with $\delta$ and $\Delta$. Cases 2 and 3 assume $\frac{C_{I} / V_{I}}{c_{I} / v_{I}}=1$, which occurs e.g. when the players have equal unit costs $C_{\mathrm{I}}=c_{\mathrm{i}}$ and evaluations $V_{\mathrm{I}}=v_{\mathrm{i}}$, and equal contest intensities for the main system and the standby system, $m_{\mathrm{M}}=m_{\mathrm{S}}=m$. For case 2 we show how this impacts the values $a, A, b, B$ of the two period system dependent on the discount parameters $\delta$ and $\Delta$. For case 3 we furthermore show the impact of no discounting $\delta=\Delta=1$.

First, inserting $m_{\mathrm{M}}=m_{\mathrm{S}}=0$ into (4),(7),(8) gives

$$
\begin{aligned}
& T_{M 1}=t_{M 1}=T_{I 2}=t_{I 2}=0, \quad p_{M 1}=p_{I 2}=\frac{1}{2}, \quad I=M, S, \\
& u_{1}=\frac{v_{M}}{2}, U_{1}=\frac{V_{M}}{2}, u_{I 2}=\frac{v_{I}}{2}, U_{I 2}=\frac{V_{I}}{2}, \quad u=\frac{v_{M}}{2}+\frac{\delta}{4}\left(v_{M}+v_{S}\right), \quad U=\frac{V_{M}}{2}+\frac{\Delta}{4}\left(V_{S}+V_{M}\right)
\end{aligned}
$$

The utilities are not affected by efforts in egalitarian contests, so the players choose zero efforts which cause $50 \%$ reliability for the main system in period 1 . The main system has $50 \%$ probability of surviving into period 2, and thus $25 \%$ reliability at the end of period 2 . The standby system has $50 \%$ probability of being implemented in period 2, and thus $25 \%$ reliability at the end of period 2 . The utilities are positive in both periods.

Second, inserting $\frac{C_{I} / V_{I}}{c_{I} / v_{I}}=1$ and $m_{\mathrm{M}}=m_{\mathrm{S}}=m$ into (8) gives

$$
a=v_{M}+\delta \frac{2-m}{4}\left(v_{M}-v_{S}\right), \quad A=V_{M}+\Delta \frac{2-m}{4}\left(V_{S}-V_{M}\right), \quad b=\delta \frac{2-m}{4} v_{S}, \quad B=\Delta \frac{2-m}{4} V_{M}
$$

giving rise to three observations. 1 . The defender gets increased value of the two period system and the attacker gets decreased value of the two period system with low contest intensity $m<2$, since $v_{S} \leq v_{M}$ and $V_{S} \leq V_{M}$. High contest intensity $m>2$ causes the reverse result and is costly for the defender. 2. Contest intensity $m=2$ gives $a=v_{\mathrm{M}}, A=V_{\mathrm{M}}, b=B=0, T_{\mathrm{M} 1}=T_{\mathrm{M} 2}$, and $t_{\mathrm{M} 1}=t_{\mathrm{M} 2}$. 3. Equal values $v_{\mathrm{S}}=v_{\mathrm{M}}$ and $V_{\mathrm{S}}=V_{\mathrm{M}}$ give $a=v_{\mathrm{M}}, A=V_{\mathrm{M}}, T_{\mathrm{M} 1}=T_{\mathrm{M} 2}$, and $t_{\mathrm{M} 1}=t_{\mathrm{M} 2}$.

Third, inserting $\frac{C_{I} / V_{I}}{c_{I} / v_{I}}=1$ and $m_{\mathrm{M}}=m_{\mathrm{S}}=m=\delta=\Delta=1$ into (4),(7),(8) gives 


$$
\begin{aligned}
& T_{M 1}=\frac{\frac{C_{M} / A}{c_{M} / a} A}{C_{M}\left(1+\frac{C_{M} / A}{c_{M} / a}\right)^{2}}, \quad t_{M 1}=\frac{C_{M} / A}{c_{M} / a} T_{M 1}, \quad p_{M 1}=\frac{1}{1+\frac{C_{M} / A}{c_{M} / a}}, \\
& T_{I 2}=t_{I 2}=\frac{V_{I}}{4 C_{I}}, \quad p_{I 2}=\frac{1}{2}, \quad I=M, S \text {, } \\
& u_{1}=\frac{v_{M}+\left(v_{M}-a\right) \frac{C_{M} / A}{c_{M} / a}}{\left(1+\frac{C_{M} / A}{c_{M} / a}\right)^{2}}, \quad U_{1}=\frac{V_{M}-A+V_{M} \frac{C_{M} / A}{c_{M} / a}}{\left(1+\frac{C_{M} / A}{c_{M} / a}\right)^{2}} \frac{C_{M} / A}{c_{M} / a}, \\
& u_{I 2}=\frac{v_{I}}{\left(1+\frac{C_{I} / V_{I}}{c_{I} / v_{I}}\right)^{2}}, \quad U_{I 2}=\frac{\left(\frac{C_{I} / V_{I}}{c_{I} / v_{I}}\right)^{2}}{\left(1+\frac{C_{I} / V_{I}}{c_{I} / v_{I}}\right)^{2}} V_{I}, \\
& u=\frac{a}{\left(1+\frac{C_{M} / A}{c_{M} / a}\right)^{2}}+b, \quad U=\frac{\left(\frac{C_{M} / A}{c_{M} / a}\right)^{2} A}{\left(1+\frac{C_{M} / A}{c_{M} / a}\right)^{2}}+B, \\
& a=\frac{5 v_{M}-v_{S}}{4}, \quad A=\frac{3 V_{M}+V_{S}}{4}, \quad b=\frac{v_{S}}{4}, \quad B=\frac{V_{M}}{4}
\end{aligned}
$$

\section{Simulating the solution}

Figs. 2-5 plot the six efforts $t_{\mathrm{M} 1}, T_{\mathrm{M} 1}, t_{\mathrm{M} 2}, T_{\mathrm{M} 2}, t_{\mathrm{S} 2}, T_{\mathrm{S} 2}$ and two utilities $u$ and $U$ as functions of one parameter relative to the baseline $c_{M}=C_{M}=c_{S}=C_{S}=v_{M}=V_{M}=v_{S}=V_{S}=m_{M}=m_{S}=\delta=\Delta=1$. The titles on the vertical axis are as specified in the legend box. Fig. 1 panel 1 plots as functions of the standby system values $v_{S}=V_{S}$ varying between 0 and 1 . When the standby system has its maximum value $v_{\mathrm{S}}=V_{\mathrm{S}}=v_{\mathrm{M}}=V_{\mathrm{M}}=1$, the six efforts equal 0.25 and the utilities are 0.5 , as also seen from (12) where $a=A=1$ and $b=B=0.25$. As $v_{\mathrm{S}}=V_{\mathrm{S}}$ decrease below 1 , the efforts $t_{\mathrm{S} 2}=T_{\mathrm{S} 2}$ decrease linearly toward zero, while $t_{\mathrm{M} 2}=T_{\mathrm{M} 2}$ remain constant at 0.25 . However, the defender compensates for the decreased value of the standby system by defending the main system more thoroughly in period 1 , and thus $t_{\mathrm{M} 1}$ increases when $v_{\mathrm{S}}=V_{\mathrm{S}}$ decrease. The attacker responds to this by decreasing $T_{\mathrm{M} 1}$ when $v_{\mathrm{S}}=V_{\mathrm{S}}$ decrease, and thus the attacker's utility $U$ also decreases when $v_{\mathrm{S}}=V_{\mathrm{S}}$ decrease. The defender's utility $u$ is almost constant (slightly $U$ shaped) since the defender compensates for the decreasing value of the standby system by defending the main system more thoroughly in period 1. Fig. 1 panel 2 plots as functions of the main system values $v_{M}=V_{M}$ increasing upwards from $v_{S}=V_{S}=1$. Now the standby system efforts $t_{\mathrm{S} 2}=T_{\mathrm{S} 2}$ remain constant at 0.25 , and all the other variables increase in $v_{\mathrm{M}}=V_{\mathrm{M}}$. Increasing $v_{\mathrm{M}}=V_{\mathrm{M}}$ relative to the fixed $v_{\mathrm{S}}=V_{\mathrm{S}}=1$ induces the defender to defend the more valuable main system more thoroughly in period 1 , and thus $t_{\mathrm{M} 1}$ increases more than $T_{\mathrm{M} 1}$, and the defender's utility $\mathrm{u}$ increases more than the attacker's utility $U$, though $t_{\mathrm{M} 2}=T_{\mathrm{M} 2}$ for the main system in period 2 increase equivalently. 


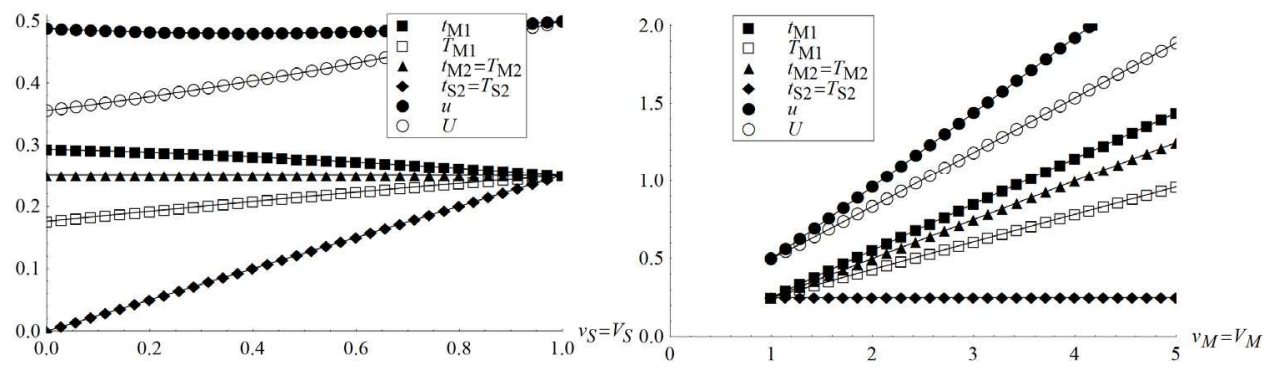

Fig. 2. Efforts $t_{\mathrm{M} 1}, T_{\mathrm{M} 1}, t_{\mathrm{M} 2}, T_{\mathrm{M} 2}, t_{\mathrm{S} 2}, T_{\mathrm{S} 2}$ and utilities $u$ and $U$ as functions of $v_{\mathrm{S}}=V_{\mathrm{S}}$ and $v_{\mathrm{M}}=V_{\mathrm{M}}$.

Fig. 3 panel 1 plots as functions of the defender's unit costs $c_{M}=c_{S}$ changing equally for both systems. The three defender efforts $t_{\mathrm{M} 1}=t_{\mathrm{M} 2}=t_{\mathrm{S} 2}$ decrease convexly and equivalently as the defense becomes more costly. The three attacker efforts $T_{\mathrm{M} 1}=T_{\mathrm{M} 2}=T_{\mathrm{S} 2}$ are inverse $U$ shaped. When $c_{\mathrm{M}}=c_{\mathrm{S}}$ is low, the inferior attacker provides modest efforts against the defender cheaply producing a substantial defense. When $c_{M}=c_{S}$ is high, the defender efforts are low and the attacker does not need to attack substantially. Hence the attacker efforts are largest for intermediate $c_{M}=c_{S}$. The defender utility decreases, and the attacker utility increases, in $c_{M}=c_{S}$. Fig. 3 panel 2 plots as functions of the defender's unit cost $c_{M}$ for the main system, keeping $c_{S}=1$ for the standby system. The results are similar but $t_{\mathrm{S} 2}=T_{\mathrm{S} 2}$ remain constant at 0.25 . When $c_{M}<1$, both the defender's and the attacker's efforts for the main system are larger in period 1 than in period 2 , and conversely when $c_{M}>1$.
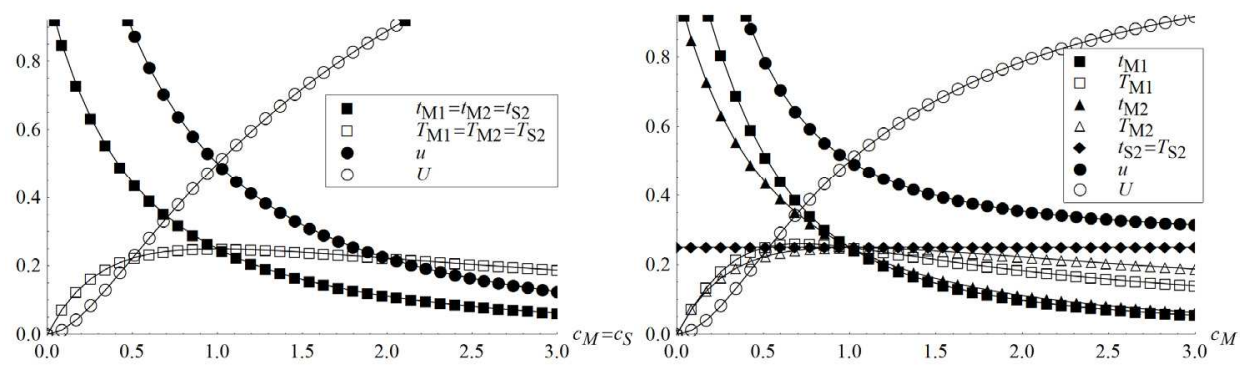

Fig. 3. Efforts $t_{\mathrm{M} 1}, T_{\mathrm{M} 1}, t_{\mathrm{M} 2}, T_{\mathrm{M} 2}, t_{\mathrm{S} 2}, T_{\mathrm{S} 2}$ and utilities $u$ and $U$ as functions of $c_{\mathrm{M}}=c_{\mathrm{S}}$ and $c_{\mathrm{M}}$.

Fig. 4 panel 1 plots as functions of equivalent contest intensities $m_{\mathrm{M}}=m_{\mathrm{S}}$ for both systems. High contest intensities induce higher efforts which increase linearly in $m_{\mathrm{M}}=m_{\mathrm{s}}$. The higher efforts are costly causing the utilities to decrease linearly reaching zero when $m_{\mathrm{M}}=m_{\mathrm{S}}=2$. Fig. 4 panel 2 plots as functions of the contest intensity $m_{\mathrm{M}}$ for the main system, keeping $m_{\mathrm{S}}=1$. Thus $t_{\mathrm{S} 2}=T_{\mathrm{S} 2}$ remain constant at 0.25 . When $m_{\mathrm{M}}<1$, the results are similar but the comparatively higher $m_{\mathrm{S}}=1$ causes lower utilities in panel 2 . For the main system in period 2 the efforts increase linearly in $m_{\mathrm{M}}$ as seen from (4) inserting $c_{\mathrm{M}}=C_{\mathrm{M}}=v_{\mathrm{M}}=V_{\mathrm{M}}=1$. However, for the main system in period 1 the efforts do not increase linearly since $A$ and $a$, instead of $v_{M}$ and $V_{\mathrm{M}}$, operate in the efforts $t_{\mathrm{M} 1}$ and $T_{\mathrm{M} 1}$ in (7). As $m_{\mathrm{M}}$ increases above $1, t_{\mathrm{M} 1}$ and $T_{\mathrm{M} 1}$ increase in a decreasing manner, reaching maxima and thereafter decreasing towards zero. 
The defender accepts its maximum for $t_{\mathrm{M} 1}$ being lower than the attacker's maximum for $T_{\mathrm{M} 1}$. This gives low reliability $p_{\mathrm{M} 1}$ for the main system in period 1 as $m_{\mathrm{M}}$ increases above 1 . The high contest intensity for the main system makes it too costly to defend and attack compared with defending and attacking the standby system in period 2. The defender's utility decreases below 0.25 as $m_{\mathrm{M}}$ increases above 1.61 , reaches a minimum 0.14 for $m_{\mathrm{M}}=2.22$ as the defender realizes that the main system is too costly to defend, and increases asymptotically towards 0.25 . Recall from (3) that if the defender does not defend the main system in period 1 , it is guaranteed to fail, $p_{\mathrm{M} 1}=0$, causing utility 0.25 generated by the standby system since $p_{\mathrm{S} 2}=0.5$ with the given parameter values. Hence the attacker's utility eventually increases towards 1.25 .
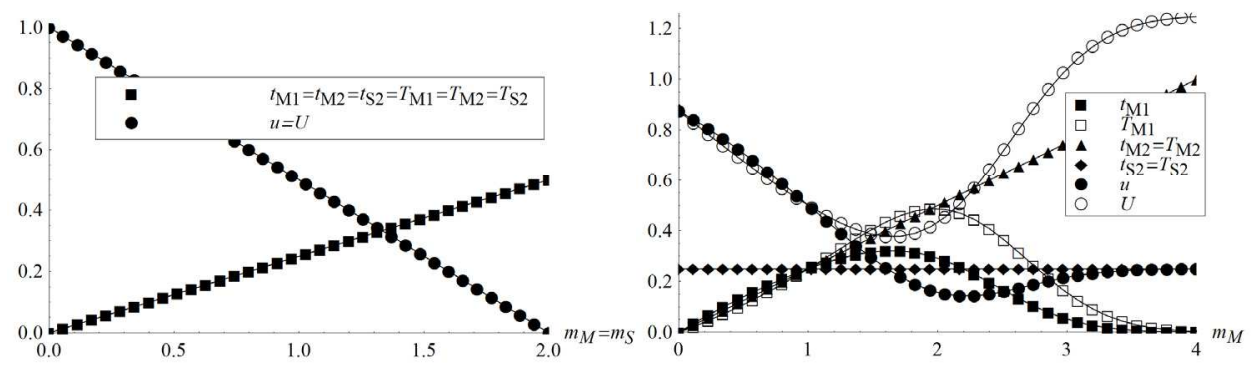

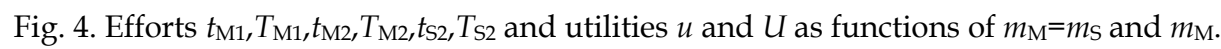

Fig. 5 panel 1 plots as functions of the discount parameters $\delta=\Delta$. All efforts are constant at 0.25 . The utilities increase from 0.25 when period 2 is discounted $(\delta=\Delta=0)$ and reliability is $p_{\mathrm{M} 1}=0.5$ for period 1, to 0.5 when both periods have equal weight $(\delta=\Delta=1)$ and all reliabilities are $p_{\mathrm{M} 1}=$ $p_{\mathrm{M} 2}=p_{\mathrm{S} 2}=0.5$. Fig. 5 panel 2 also plots as functions of $\delta=\Delta$, but decreases the values of the standby system to $v_{\mathrm{S}}=V_{\mathrm{S}}=0.5$. This decreases the efforts for the standby system to $t_{\mathrm{S} 2}=T_{\mathrm{S} 2}=0.125$. The utilities remain at 0.25 when $\delta=\Delta=0$ and period 2 is irrelevant. As $\delta=\Delta$ increase, the defender compensates for the less valuable standby system by increasing $t_{\mathrm{M} 1}$ from 0.25 to 0.28 when $\delta=\Delta=1$, which increases the reliability of the main system in period 1 . The attacker decreases $T_{\mathrm{M} 1}$ from 0.25 to 0.22 when $\delta=\Delta=1$, while $t_{\mathrm{M} 2}=T_{\mathrm{M} 2}$ remain constant at 0.25 . The defender's utility thus increases more than the attacker's utility, but both utilities increase less than in panel 1 where the standby system is more valuable at $v_{\mathrm{S}}=V_{\mathrm{S}}=1$.
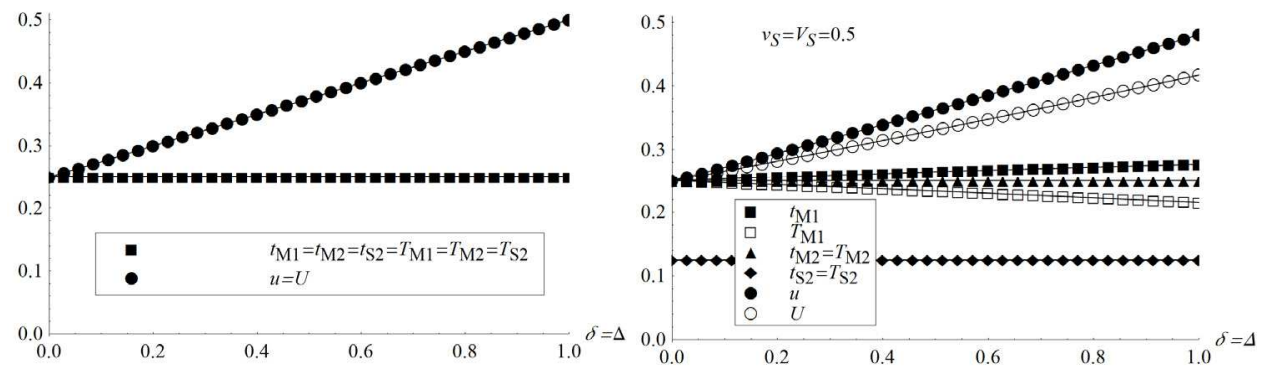

Fig. 5. Efforts $t_{\mathrm{M} 1}, T_{\mathrm{M} 1}, t_{\mathrm{M} 2}, T_{\mathrm{M} 2}, t_{\mathrm{S} 2}, T_{\mathrm{S} 2}$ and utilities $u$ and $U$ as functions of $\delta=\Delta$. 


\section{Examples}

There are no limits to the kinds of standby systems that can be envisioned. In fact, any system produced to deliver some function, can be supplemented with a standby system to deliver the same function in the event that the main system breaks down. Examples of systems are power supply, telecommunications systems, water supply, roads, bridges, tunnels, political and economic institutions, businesses, schools, hospitals, recreational facilities, and various assets. One example of a standby system is a standby generator which is a back-up electrical system that operates automatically (Hickey 2002). Within seconds of a utility outage, an automatic transfer switch senses the power loss, directs the standby generator to start, and transfers the electrical load to the standby generator. The standby generator thereafter supplies power to the circuits. To ensure a proper response to a power outage, a standby generator runs weekly self-tests. Most units run on diesel, natural gas or liquid propane gas. Automatic standby generators may be required by building codes for critical safety systems. Examples are building elevators, fire protection systems, standby lighting, or medical and life support equipment. Residential standby generators are common, providing backup electrical power to security systems, household appliances such as refrigerators, stoves, and hot water heaters, and HVAC systems. To determine the quality, design, and maintenance regime for the main system and standby system in each particular example, the analysis in this paper can be used.

\section{Conclusion}

We consider two players choosing strategies through time to impact the reliability of a dependent system which consists of a main system and a standby system. Each system can be in two states, i.e. it can operate or fail. If the main system operates successfully through period 1, it continues to operate into period 2 and the standby system remains in standby. If the main system fails in period 1, the standby system is implemented in period 2.

Each system is protected by a defender which maximizes its reliability subtracting the defense costs, and attacked by an attacker which maximizes its unreliability subtracting the attack costs. Each system's reliability depends on the relative levels of defense and attack and on the contest intensity. Each player's utility depends additively on the system reliability in two time periods, with a time discount parameter for the second period. The unit costs of effort and the contest intensities are different for the two players and the two systems. The two period game is analyzed with backward induction.

In period 1 the defender chooses a defense effort and the attacker chooses an attack effort for the main system. In period 2 the defender chooses one defense effort for the main system and one defense effort for the standby system, not knowing before the game starts whether the main system or the standby system is the system to be defended in period 2 . Analogously in period 2, the attacker chooses one attack effort for the main system and one attack system for the standby system. Hence six strategic decisions are made by the two players.

The players assign different values to the main system and the standby system. We present analytical solutions and simulations to illustrate the players' efforts in the two periods and the utilities dependent on parametric changes. 
Each time period can be short or long, e.g. minutes, days, months, as determined by the nature of the system and how failures occur dependent on the players' efforts. Since the main system fails in period 1 with positive probability, period 2 starts with the standby system with this positive probability.

Before period 1 each player assesses its effort for period 1 knowing that this effort impacts the probability that the main system survives into period 2. Exerting low defense effort in period 1 increases the probability that the standby system is implemented in period 2 . We show that as the value of the standby system decreases below that of the main system, the defender increases its defense of the main system in period 1. Increasing the value of the main system increases the defender's utility more than the attacker's utility since the defender defends the main system more thoroughly in period 1. High defense effort in period 1 is an investment into the future for the defender.

As the defender's unit defense costs increases, its efforts and utilities decrease while the attacker's efforts are inverse $U$ shaped and its utility increases. This follows since low unit defense costs make it not worthwile for the inferior attacker to attack, while high unit defense costs make it unnecessary for the superior attacker to attack substantially.

Increasing contest intensities for both systems causes all efforts to increase driving utilities downwards eventually reaching zero. Increasing the contest intensity only for the main system causes both efforts for the main system in period 1 to be inverse $U$ shaped but taller for the attacker. This increases the probability that the main system fails in period 1 . This benefits the attacker and does not benefit the defender which resorts to defending the standby system in period 2. Increasing discount parameters, making period 2 more valuable, benefit both players.

Two limitations of Markov analysis have been illustrated in this paper. First, we have enabled players to choose efforts strategically, which violates the Markov property. Second, we have relaxed the constraint in Markov modeling where the transition rates between different states are kept constant through time. The parameter values for the standby system in period 2 may differ from the parameter values for the main system in period 1. Future research may model in a multi-period game multiple states of operation for the main system and the standby system, and repair of the main system.

\section{Notation}

$t_{\mathrm{Mj}}$ defender's effort to protect main system in period $\mathrm{j}, \mathrm{j}=1,2$

$T_{\mathrm{Mj}} \quad$ attacker's effort to attack main system in period $\mathrm{j}, \mathrm{j}=1,2$

$t_{\mathrm{S} 2} \quad$ defender's effort to protect standby system in period 2

$T_{\mathrm{S} 2} \quad$ attacker's effort to attack standby system in period 2

$p_{\mathrm{Mj}} \quad$ reliability of main system in period $\mathrm{j}$

$p_{\mathrm{S} 2} \quad$ reliability of standby system in period 2

$c_{\mathrm{M}} \quad$ defender's unit cost of effort for main system

$C_{\mathrm{M}} \quad$ attacker's unit cost of effort for main system

$c_{S} \quad$ defender's unit cost of effort for standby system

$C_{S} \quad$ attacker's unit cost of effort for standby system

$v_{M} \quad$ defender's value of operational main system given presence of a standby system

$V_{\mathrm{M}} \quad$ attacker's value of operational main system given presence of a standby system 
$v_{\mathrm{S}} \quad$ defender's value of standby system

$V_{\mathrm{S}} \quad$ attacker's value of standby system

$m_{\mathrm{M}} \quad$ attacker-defender contest intensity for main system

$m_{\mathrm{S}} \quad$ attacker-defender contest intensity for standby system

$\delta \quad$ defender's time discount parameter for period 2

$\Delta \quad$ attacker's time discount parameter for period 2

a defender's value of an operational two period system

A attacker's value of an operational two period system

$b \quad$ additional value to defender of two period system

$B \quad$ additional value to attacker of two period system

u defender's utility

U attacker's utility

\section{References}

Azaiez, N., Bier, V.M. (2007). Optimal Resource Allocation for Security in Reliability Systems. European Journal of Operational Research 181, 2, 773-786.

Bier, V.M., Nagaraj, A., Abhichandani, V. (2005). Protection of Simple Series and Parallel Systems with Components of Different Values. Reliability Engineering and System Safety 87, 315-323.

Bier, V.M., Oliveros, S., Samuelson, L. (2006). Choosing What to Protect: Strategic Defense Allocation Against an Unknown Attacker. Journal of Public Economic Theory 9, 4, 563-587.

Dighe, N., Zhuang J., and Bier V.M. (2009). Secrecy in defensive allocations as a strategy for achieving more cost-effective attacker deterrence, International Journal of Performability Engineering, special issue on System Survivability and Defense against External Impacts, 5, 1, 31-43.

Ebeling, C. (1997). An introduction to Reliability and Maintainability Engineering, McGrawHill, New York.

Enders, W., Sandler, T. (2003). What do we know about the substitution effect in transnational terrorism?. in A. Silke and G. Ilardi (eds) Researching Terrorism: Trends, Achievements, Failures (Frank Cass, Ilfords, UK), http://wwwrcf.usc.edu/ tsandler/substitution2ms.pdf

Hausken, K., (2005) Production and conflict models versus rent seeking models. Public Choice 123, 1, 59-93.

Hausken, K. (2006), Income, Interdependence, and Substitution Effects Affecting Incentives for Security Investment, Journal of Accounting and Public Policy 25, 6, 629-665.

Hausken, K. (2007), Stubbornness, Power, and Equilibrium Selection in Repeated Games with Multiple Equilibria, Theory and Decision 62, 2, 135-160.

Hausken, K. (2008), Strategic Defense and Attack for Series and Parallel Reliability Systems, European Journal of Operational Research 186, 2, 856-881.

Hausken, K. (2010), Defense and Attack of Complex and Dependent System, Reliability Engineering \& System Safety 95, 1, 29-42.

Hausken, K. (2011), Game Theoretic Analysis of Two Period Dependent Degraded Multistate Reliability Systems, International Game Theory Review Forthcoming.

Hausken, K. (2011), Protecting Complex Infrastructures Against Multiple Strategic Attackers, International Journal of Systems Science 42, 1, 11-29. 
Hausken, K. and Levitin, G. (2009), Minmax defense strategy for complex multi-state systems, Reliability Engineering \& System Safety 94, 2, 577-587.

Hickey, R.B. (2002). Electrical Construction Databook, McGraw Hill, New York, Chapter 14.

Hirshleifer, J. (1995). Anarchy and Its Breakdown. Journal of Political Economy 103, 1, 26-52.

Keohane N., Zeckhauser R.J. (2003). The ecology of terror defense. Journal of Risk and Uncertainty 26, 201-229.

Levitin, G., (2007). Optimal Defense Strategy Against Intentional Attacks. IEEE Transactions on Reliability 56, 1, 148-156.

Levitin, G. (2009). Optimizing Defense Strategies for Complex Multi-State Systems. In: Bier VM and Azaiez MN (eds.), Game Theoretic Risk Analysis of Security Threats, Springer, New York, 33-64.

Levitin, G. and Hausken, K. (2009), Redundancy vs. Protection vs. False Targets for Systems under Attack, IEEE Transactions on Reliability 58, 1, 58-68.

Lisnianski, A. and Levitin, G. (2003), Multi-state system reliability. Assessment, optimization and applications, World Scientific, New Jersey.

Nitzan, S. (1994), Modelling Rent-Seeking Contests, European Journal of Political Economy 10, 1, 41-60.

Ramirez-Marquez, J.E. and Coit, D.W., (2005). A Monte-Carlo simulation approach for approximating multi-state two-terminal reliability, Reliability Engineering \& System Safety 87, 2, 253-264.

Skaperdas, S., (1996). Contest success functions. Economic Theory 7, 2, 283-290.

Taylor H.M., Karlin S., (1998), An Introduction To Stochastic Modeling, Third Edition, Academic Press, New York.

Tullock, G. (1980). Efficient Rent-Seeking. In Buchanan, J.M., Tollison, R.D., and Tullock, G., Toward a Theory of the Rent-Seeking Society, Texas A. \& M. University Press, College Station, 97-112.

Zio, E. and Podofillini, L. (2003), Monte Carlo simulation analysis of the effects of different system performance levels on the importance of multi-state components, Reliability Engineering \& System Safety 82, 1, 63-73. 


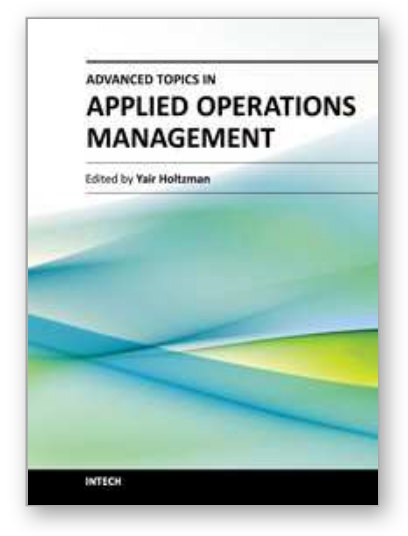

\author{
Advanced Topics in Applied Operations Management \\ Edited by Mr. Yair Holtzman
}

ISBN 978-953-51-0345-5

Hard cover, 200 pages

Publisher InTech

Published online 16, March, 2012

Published in print edition March, 2012

The chapters in Advanced Topics in Applied Operations Management creatively demonstrate a valuable connection among operations strategy, operations management, operations research, and various departments, systems, and practices throughout an organization. The authors show how mathematical tools and process improvements can be applied effectively in unique measures to other functions. The book provides examples that illustrate the challenges confronting firms competing in today's demanding environment bridging the gap between theory and practice by analyzing real situations.

\title{
How to reference
}

In order to correctly reference this scholarly work, feel free to copy and paste the following:

Kjell Hausken (2012). Game Theoretic Analysis of Standby Systems, Advanced Topics in Applied Operations Management, Mr. Yair Holtzman (Ed.), ISBN: 978-953-51-0345-5, InTech, Available from:

http://www.intechopen.com/books/advanced-topics-in-applied-operations-management/game-theoreticanalysis-of-standby-systems

\section{INTECH}

open science | open minds

\section{InTech Europe}

University Campus STeP Ri

Slavka Krautzeka 83/A

51000 Rijeka, Croatia

Phone: +385 (51) 770447

Fax: +385 (51) 686166

www.intechopen.com

\section{InTech China}

Unit 405, Office Block, Hotel Equatorial Shanghai

No.65, Yan An Road (West), Shanghai, 200040, China

中国上海市延安西路65号上海国际贵都大饭店办公楼 405 单元

Phone: +86-21-62489820

Fax: +86-21-62489821 
(C) 2012 The Author(s). Licensee IntechOpen. This is an open access article distributed under the terms of the Creative Commons Attribution 3.0 License, which permits unrestricted use, distribution, and reproduction in any medium, provided the original work is properly cited. 